\title{
ASSOCIATION OF TUMOR CELLS CHEMORESISTANCE MECHANISMS AND SUBOPTIMAL SYSTEMIC CYTOTOXIC TREATMENT RESULTS
}

\author{
LJUBICA VAZDAR, ROBERT ŠEPAROVIĆ, ANA TEČIĆ VUGER, \\ MIRJANA PAVLOVIĆ, NIKOLINA LONJAK and CHIARA KRSTIĆ
}

Department of Medical Oncology, Division of Radiotherapy and Medical Oncology, University Hospital for Tumors, Sestre milosrdnice University Hospital Center, Zagreb, Croatia

\begin{abstract}
Summary
Systemic cytotoxic chemotherapeutic treatment of malignant tumors does not fully meet its goal due to the resistance of present tumor cells to the applied therapy. Chemoresistance is complex and multifactorial, caused by numerous mechanisms that alter drug concentration in the cell, by changes in expression of the epidermal growth factor and by activation of intracellular signaling pathways PI3K / Akt and MAPK. The factor of chemoresistance is also an increased level of antioxidative glutathione and glutathione transferase $-S$ enzyme and the presence of tumor stem cells that significantly improve protection of DNA from damage. Apart from cellular factors, resistance is influenced by extracellular hypoxia and acidosis and autophagy.

Overcoming the chemoresistance is possible by using nanomechanisms for delivery of drugs to tumor cells, autophagy inhibitors like antimalarials chloroquine and hydroxychloroquine and plant polyphenols.

By better understanding the mechanisms of chemoresistance and it's overcoming it can be possible to achieve improvement in antitumor treatment.
\end{abstract}

KEY WORDS: chemoresistance, malignant tumor, tumor cell, cytotoxic treatment

\section{POVEZIVANJE MEHANIZAMA KEMOREZISTENTNOSTI TUMORSKIH STANICA I SUBOPTIMALNIH SISTEMSKIH CITOTOKSIČNIH REZULTATA LIJEČENJA}

\section{Sažetak}

Sustavno citotoksično kemoterapijsko liječenje zloćudnih tumora ne ispunjava u potpunosti svoj cilj zbog prisutne kemorezistencije tumorskih stanica na primjenjenu terapiju. Kemorezistencija je kompleksna i uzrokovana brojnim mehanizmima koji mijenjaju koncentraciju lijeka u stanici, promjenama u ekspresiji epidermalnog čimenika rasta i aktivacije unutarstaničnih signalnih puteva PI3K/Akt i MAPK. Čimbenik kemorezistencije je porast antioksidativnog enzima glutationa i glutation-S transferaze te prisustvo matičnih stanica karcinoma koje značajno bolje štite DNA od oštećenja. Osim staničnih čimbenika, na rezistenciju utječe ekstracelularna hipoksija i acidoza te autofagija.

Prevladavanje kemorezistencije moguće je primjenom nanomehanizama u dostavi lijekova u tumorske stanice, inhibitorima autofagije antimalaricima klorokinom i hidroksiklorokinom te biljnim polifenolima.

Poznavanjem mehanizama kemorezistencije i njezinim nadilaženjem moguće je poboljšati dobrobit antitumorskog liječenja.

KLJUČNE RIJEČI: kemorezistencija, zloćudni tumor, tumorska stanica, citotoksično liječenje 


\section{INTRODUCTION}

Systemic cytotoxic chemotherapeutic treatment of malignant tumors does not fully meet its goal due to the present tumor cell chemoresistance to the applied therapy. Chemoresistance is complex and multifactorial, caused by a number of mechanisms that alter cell proliferation and apoptosis. Mechanisms of chemoresistance include changes in signal pathways in the tumor cell, changes in transport proteins and gene polymorphisms that alter pharmacokinetics and drug distribution, changes in tumor microenvironment, and presence of tumor stem cells that effectively protect their DNA from damage. Numerous potential inhibitors of chemoresistance are being investigated, and today, antimalarials and plant polyphenols are available for therapeutic purposes.

Knowing and overcoming mechanisms of chemoresistance represents benefit of antitumor treatment, with reducing the risk of relapse and improving overall survival.

\section{MECHANISMS OF TUMOR CELL CHEMORESISTANCE}

\section{Chemoresistance}

The onset of tumor is a result of alterations in the genome and the breakdown of normal biological processes within the cell. Chemotherapy is one of the standard methods of treating many types of tumors, but there are still failures of treatment, with relapse and progression of the disease. The failure of chemotherapy treatment in $90 \%$ of cases is attributed to the chemoresistance of tumor cells. (1) The manifestations of resistance are divided into intrinsic and acquired, and both are multifactorial caused. (1)

Significant mechanisms contributing to cellular resistance include: increased expression of factors that reduce intracellular drug concentration, drug - tumor cell interaction alterations, and cellular response changes, with apoptotic pathways disorders and disorders in reparation of damaged DNA. (1)

\section{Gene polymorphism and immune cells}

Polymorphisms of genes responsible for drug metabolism affect the pharmacokinetics and dynamics of drugs. By identifying polymorphisms, a personalized approach to treatment is possible, with an additional increase in survival rates. It is especially important to identify cytochrome P450 (CYP) and glutathione S-transferase polymorphisms. (2)

Significant mechanism of chemoresistance includes immune cells, which is particularly evident in malignant melanoma. Anti-tumor immunity plays an important role in activated CD4 + and CD8 + T cells, dendritic cells and NK cells. NK cells prevent the formation of metastases, especially in the liver. (3) Research findings show that: CD4 + and CD8 + T cells, dendritic cells and NK cells prevent melanoma metastases in the distal organs. (3)

\section{Signaling through growth factors and mechanisms of cell cycle control}

Epidermal growth factor receptor (EGFR) activation and tyrosine kinase phosphorylation activate intracellular signaling pathways of PI3K / Akt and inhibit chemotherapy-induced apoptosis. Amplified PI3K / Akt were found in 30-40\% of ovarian cancer. Excess expression of EGFR and HER2 receptors in ovarian cancer has been associated with poor prognosis and lower antitumor response. (4) Tumor suppressor gene $\mathrm{p} 53$ regulates expression of p21 (cyclin-dependent kinase, CDK1) and leads to cell cycle arrest in the G1 phase. Changes in the p53 gene are present in $50-70 \%$ of serous ovarian adenocarcinoma. Since cytotoxic drugs are effective in proliferating cells, this activation leads to inefficiency of the drug. Changes in the p53 gene were found in $50-70 \%$ of cases of the advanced serous ovarian adenocarcinoma. Another important factor in the control of the cell cycle is the nuclear antigen $\mathrm{Ki}-67$, its level is significantly higher in the chemotherapy responders, and it represents a prognostic factor. Considering the above mentioned, numerous new therapeutic strategies have been explored, i.e. targeted drugs acting on HER2 (trastuzumab), EGFR inhibitors (gefitinib, erlotinib), anti-VEGF (bevacizumab). (4)

\section{The role of glutathione and glutathione-S transferase}

Glutathione (GSH) plays an important role in many cellular processes, such as cellular differentiation, proliferation, and apoptosis, it is involved in etiology and the progression of many diseases. 
Deficiency of GSH or reduction in the ratio of GSH / glutathione disulfide (GSSG) leads to increased sensitivity to oxidative stress involved in cancer progression. Reactive oxygen radicals (ROS) accumulate during cellular damage, and more antioxidants are produced compensatively. In the context of tumor progression, the effect of antioxidant therapy is positive. Prooxidant therapies, including radiation and chemotherapy, leading to the collapse of the oxidative system and cell death. Many tumors have significant over-expression of antioxidant enzymes, especially GSH, which results in resistance of tumor cells to drugs. The main investigations are based on depletion of GSH or GSH tripeptide BSO (glutathione sulfoximine). (5) Glutathione is important in cell proliferation and affects the activity of ribonucleotide reductase that limits the synthesis of DNA. Mitochondrial GSH dysfunction is a well-known mechanism for cell death, present in small - cell lung cancer, resistant to conventional treatments. Increased levels of GSH have been found in ovarian, colon and liver cancer, melanoma and leukemia. (5) A promising therapeutic strategy for overcoming tumor progression and tumor chemoresistance is modulating the GSH antioxidant redox system. A series of chemically modified analogs and precursors that copy the physiological effects of GSH (N-acetylcysteine, YM8737, NAC, S-nitrosoglutathion) are produced. The direct anti-tumor effect is produced by drugs that target S-glutamylation (NOV-002), combined with standard chemotherapeutic drugs. The other approach is the inhibition of Nrf2 signal pathways, which increases the sensitization of chemoresistant tumors (brusatol). (5) Glutathione-S transferase (GST) is a family of phase II detoxification enzymes that catalyze glutathione conjugation (GSH) in a wide spectrum of endogenous and exogenous electrophilic components. It is believed that GST leads to resistance by direct detoxification or inhibition of the MAP kinase pathway. There is a correlation between GST expression and susceptibility to alkylating agents. Drugs that are associated with increased levels of GST and resistance are chlorambucil, melphalan, acrolein, carmustine, steroids. Etacrynic acid EA inhibits GST $-\alpha,-\mu$ and $-\pi$ by direct binding to the site of binding of the substrate to the isoenzyme, as well as by reduction of its co-factor by GSH conjugation. It potentiates the cytotoxic effect of chlorambucil in cell lines of hu- man colorectal cancer and melphalan in mice with SCID. (6)

\section{Phospho-inositol - 3 kinase pathways}

In response to the activation of tyrosine $\mathrm{ki}-$ nase receptor (RTKs) and G-protein receptors (GPCRs), the PI3K / Akt and mTOR signal pathway promotes tumorigenesis with increased proliferation and reduced apoptosis. The PI3K pathway is recognized as an important anti-tumor drug resistance factor, and the incidence of this resistance increases rapidly. Activation of PI3K is associated with reduced susceptibility to doxorubicin and paclitaxel, where increased expression of Mcl1 antiapoptotic proteins contribute to resistance. The PI3K signal pathway may result in resistance to endocrine therapy, with estrogen inhibitor tamoxifen, RTK inhibitors and antiangiogenic therapy with bevacizumab. The activity of PI3K pathway proved to be a predictive factor for responding to RTKs inhibitors and contributes to resistance to RTs inhibitors, including gefitinib and trastuzumab. (7) PI3K path helps in resistance to immunotherapy and is associated with enhanced expression of anti-apoptotic proteins, including Mcl1. The PI3K hyperactivity caused by the loss of PTEN is associated with increased PD-L1 excretion, which plays an important role in suppressing the immune system. Incomplete inhibition of PI3K pathway, by insufficiently high drug dose, limited by toxicity, promotes resistance. Resistance to PI3K inhibitors can be derived from mechanisms promoting the reactivation of PI3K signaling, mTORC1 suppression over RTKs is interrupted and FOXOdependent activation of RTK expression is stimulated. Activation of alternative survival pathways (MAPK pathway activation) and MAPK pathway therapeutic inhibition enhance the antitumor activity of PI3K inhibitors. (7)

\section{AUTOPHAGY AND CHEMORESISTANCE}

Autophagy is the evolutionary retention of the catabolic process of the cell itself and is a response to microcellular stressors. Current findings are that autophagy can act as a "guardian" that eliminates damaged cellular elements and thus protects against tumor formation, and in developed tumors acts as a protective mechanism. However, excessive autophagy can lead to cell 
death, especially after treatment with chemotherapeutics inducing apoptosis or autophagy cell death. Many anticancer drugs stimulate autophagy by inhibiting the PI3K / Akt / mTOR signal pathway or by altering the genetic (epigenetic) phenotype of tumor cells. Just as autophagy has the potential to induce cell death or promote survival, there is more and more evidence that autophagy has a paradoxical role after antitumor therapy, when it can result in increased or decreased antitumor activity. During chemotherapy, it is activated as a protective mechanism and autophagy inhibition can, in this case, lead to the susceptibility of proliferating resistant cells. On the other hand, autophagy can lead to cell death. Antitumor drugs appear to induce different effects of autophagy in different tumors. Studies have shown that tumor resistance to radiotherapy, chemotherapy, and targeted therapy can be further enhanced by autophagy mechanisms, and therefore autophagy inhibition may enhance chemotherapy toxicity, especially if there is a combination of several different drugs. (8) The only autophagy inhibitors whose efficacy and safety has been demonstrated in vivo, chloroquine (CQ) and its hydroxychloroquine derivative (HCQ), block auto-phagosomal fusion and degradation. Both drugs were investigated in preclinical and clinical studies. There is evidence that epirubicin could induce autophagy in MCF-7 tumor cells, resulting in the protection of these cells from apoptosis induced by epirubicin. Autophagy is also considered to be a key mechanism in anti-estrogen resistance. (8) Studies have shown that inhibition of autophagy leads to an anti-cancer effect of chemotherapy or targeted therapy in colorectal cancer. Recently, it has been shown that MAPK14 / p38 protein is involved in resistance to carcinoma cells at 5-FU and irinotecan, which acts as a trigger to autophagy to protect tumor cells from the cytotoxic activity. The combination of inhibition of autophagy and chemotherapy or targeted therapy promises a lot in the treatment of HCC. Autophagy is activated in HCC after treatment with oxaliplatin, and autophagy suppression increases the cytotoxic effect of oxaliplatin. Combination of autophagy inhibition and bevacizumab has been shown to significantly reduce tumor growth. Also, a combination of sorafenib and CQ can lead to increased death of tumor cells. (8) EGFR-TK inhibitors are widely used in patients with non-squa- mous lung cancer. The efficacy of these drugs is limited due to naturally acquired resistance. Autophagy can be induced by erlotinib or gefitinib, EGFR-TKIs. Furthermore, CQ has proven to be a drug that can lead to improved sensitivity to chemotherapy and radiation in several preclinical models. CQ not only potentiates topotecan cytotoxicity, but may also enhance the effect of the PI3K / mTOR inhibitor NVP-BEZ235 on induction of apoptosis, inhibition of colonization, and suppression of xenograft on mice. Stage I study in patients with advanced nonsquamous lung cancer, who demonstrated the prior clinical benefit of EGFR-TKIs, showed that HCQ with or without erlotinib is safe and Phase II is recommended, in which the erlotinib dose would be $150 \mathrm{mg}$ daily and HCQ $1000 \mathrm{mg}$ daily. (8) Several studies have shown that autophagy acts as a survival factor and leads to chemoresistance in prostate and kidney cancer. Activation of autophagy protects tumor cells from cell death, while inhibition of autophagy suppresses PC-3, a growth factor in prostate cancer cells in vivo. Administration of high doses of interleukin 2 (HDIL-2) has shown a partial or complete response to therapy in some patients with metastatic kidney cancer. However, treatment (HDIL-2) is often limited by side - effects due to cytokine-induced systemic autophagy syndrome. The combination of IL-2 and CQ has been shown to enhance antitumor activity, with reduced toxicity, compared to IL-2 alone, which is a new area of research and strategy to improve HDIL-2 immunotherapy in patients with kidney cancer. Autophagy could be one of the factors in resistance to the drugs of patients with clear cell ovarian cancer. The NAC- 1 protein can mediate cisplatin resistance by activating autophagy. In this case, inhibition of autophagy would also lead to necrosis and cell tumor calming. A combination of sorafenib and HCQ for FIGO III and IV ovarian carcinoma was investigated. In addition to antimalarials, the ablation of autologous regulator genes Beclin 1, ATG 5, ATG6, ATG7, and ATG12 has been shown to result in increased sensitivity to chemotherapeutics.

Various autophagy inhibitors block the process at different levels. Chloroquine and its derivatives are currently the only autophagy inhibitors available for treatment of patients. In the studies, HCQ is often used in combination with chemotherapy, radiation therapy, targeted therapy or 
immunotherapy. These two drugs can inhibit autophagy-mediated survival mechanisms and lead to antitumor effect enhancement. (8)

\section{ADAPTIVE RESISTANCE IN BREAST CANCER}

The appearance of recurrence and metastasis of the primary tumor after antitumor therapy is a challenge to successful treatment strategies. Radiotherapy is a powerful tool to control tumor growth, however, the tumor develops an adaptive response to radiotherapy and becomes more resistant and aggressive. HER2 is a marker for the resistance of cancer stem cells (CSC) to radiotherapy. Clinical data show that patients suffering from breast cancer with increased HER2 expression live by one third shorter than HER2 negative tumors. Tumor radiosensitivity creates a major challenge for the treatment of cancer, and CSCs have proved to be more resistant than non-CSC cells. CSC is believed to be responsible for the failure of therapy and tumor relapses. Repopulation of cancer cells after treatment has long been considered a cause of failure of treatment. (9) One of the main characteristics of the stem cells as well as CSC is that they can significantly better protect DNA from harmful effects than non-stem cells. Radiation causes cell death by causing difficult repair of DNA. More evidence supports the link between radiosensitivity and signaling of DNA damage. Therapeutic ionizing radiation (IR) leads to DNA damage and oxidative stress which activates specific signal pathways in the irradiated cells. Depending on the level of DNA damage, either survival or apoptotic mechanisms will be triggered. Philips et al. have shown that the NOtch signal pathway activates in CSC of breast cancer after exposure to radiation via PI3K, leading to an increased number of CSC. (9) Enhanced HER2 expression exists in $15-30 \%$ of patients and is associated with more aggressive tumor growth, increased recurrence risk, and resistance to therapy. HER2 is a proto-oncogene located on the long arm of chromosome 17 and encodes the expression of the HER2 glycoprotein receptor on the tumor cell membrane. Discovery of epidermal growth factor receptor (EGFR) and later anti-HER2 monoclonal antibodies to trastuzumab represents a significant advance in the treatment of breast cancer. Data suggests that HER2 is a marker for radiosensitive CSC. Thus,
HER2 negative cancer can "wake up" the mute HER2 expression after radiation, which explains the potential benefit of anti-HER2 treatment in primary HER 2 negative breast cancer. Breast cancer cells that have poor HER2 expression before radiation may become radioresistant due to increased expression of HER2 and/or Her2-NF-kBHer2 loop, activated after ionizing radiation. (9)

\section{OVERCOMING MULTIPLE DRUG RESISTANCE}

\section{Nanomechanisms of drug delivery to tumor cells}

Potential Multi-Drug Resistance (MDR) factors include increased drug detoxification, reduced drug intake, increased intracellular levels of nucleophiles, enhanced drug repair of drug-induced cell damage, overexpression of drug transporter (P-glycoprotein / P-gp, MRP1, and 2-multidrug resistance-associated proteins, $\mathrm{BCRP}$-breast cancer resistance protein). Current nanoparticles such as polymeric nanoparticles, liposomes and mycelium are innovative platforms for the treatment of tumor cell multiresistance. Nanomechanisms have the potential to improve the therapeutic drug index. (10) Resistance to drugs is a result of a reduction in the effective drug concentration in the cell. Numerous resistance mechanisms are known: increased expression of the efflux pumps (P-gp, MRP1, BCRP), drug elimination and drug detoxification, drug sequestration within liposomes or endosomes, reduced drug intake due to altered carriers, inactivation of the drug via glutathione-mediated reductions, drug-binding sites, increased DNA repair capacity through topoisomerase II, decreased apoptosis, hypoxia-regulated expression of MDR-related genes such as ABCtransporter, Bcl2 family of genes, glutathione, metalloproteins etc. (by activation of HiF1 transcription factors). (7) Recurrent metastatic ovarian cancer is usually resistant to multiple chemotherapeutics. The hypothesis of resistance is based on the presence of stem cells (cancer stem cells / CSC) that can overcome the effect of chemotherapy and metastasize. ABCB1 is a cell transporter that is enhanced in a paclitaxel-resistant cell line. (10) Forkhead box (Fox) transcription factors are proteins that play a key role in the regulation of numerous biological binding processes for specific DNA sequences. The most important are FxO3a that is a 
tumor suppressor, FoxM1 that is an oncogene and FoxA that has the ability to initiate transcription genes. Oncogene myc is negatively regulated by FoxO3a, which can play a key role in controlling cellular metabolism during initiation and cancer progression. (11) Decreased intracellular accumulation of drugs in resistant leukemia cells is not only MDR efflux-mediated but also by reduced cellular confluence. Reduced drug accumulation in resistant cells is explained by the possibility of expulsion. Resistant cells have an overexpression of $\mathrm{ABCB} 1$ conveyor which expel the medicament from the target cells and targeted competitive inhibitors have produced that bind to the transporter, with at least the same affinity as a medicament. However, the intracellular drug concentration is the balance between the drug accumulation due to the intake and its clearance by the efflux. The current model assumes that drug intake is constant, but resistance may be a consequence of reduced endocytosis / cytotoxic drug inflammation. (12)

\section{Tumor microenvironment and strategies to overcome chemoresistance}

Hypoxia (partial oxygen pressure lower than $10 \mathrm{mmHg}$ ) and acidity with low levels of nutrients are key factors of the tumor microenvironment. Acidity causes activation of proteases, rising in permeability of the vasculature, with the increase of interstitial pressure and the rise of the P-gp level. Hypoxia activates the HIF-1 transcriptional factor that induces resistance and metastasis. Acidity extracellularly reduces doxorubicin and mitoxantrone cellular influx, while hypoxia regulates angiogenic VEGF, placental growth factor (PGF), TGF $\alpha$, IL-8 and hepatocyte growth factor (HGF). (13) The strategies for overcoming the MDR by expression of genes encoding P-go transporter, MDR-1 or Survivin RNA interference (RNAi) or RNA (small interfering RNA) are studied. In the studies, chemically synthesized siRNAs that reduce MDR1 / P-gp mRNA and protein expression and anti-ABC transporter shRNA have a high potential for MDR. Monoclonal antibodies to P-gp (Mabs) have the potential of targeting P-gp and killing MDR tumor cells. (13) Then there is a development of antitumor drugs that do not substrate P-gp: taxanes are not recognized by P-go transporter, $\mathrm{ABC}$ transporter inhibitors, nanosomes - different types of nanoparticles (polymeric, solid lipid, magnetic nanoparticles, mesopore silicones, liposomes, mycelial). Nanosilicants overcome the challenge of bioavailability and ABC-mediated drug efflux. (13)

\section{Chemosensitization and radiosensitization of tumors with plant polyphenols}

Many plant polyphenols: genistein, piperine, curcumin, resveratrol, silymarin, caffeic acid phenethyl ester, flavopiridol, hemodynes, green tea polyphenols, oleandrine, ursolic acid, and betulinic acid have been investigated in tumor sensitization to applied chemo and radiotherapy. Research has shown their role in inhibiting cellular pathways that lead to resistance and are also protective in therapy-induced toxicity. Numerous photochemical agents are associated with blockade of initiation and tumor development by acting on the pathways of MAP kinase and PI-3K. The activation of the NF- $\kappa B$ transcription factor by chemotherapy and radiation can lead to treatment-induced resistance, inhibits chemotherapyinduced apoptosis. Expression of COX-2-enzyme is associated with poor treatment outcome and in many studies investigated selective COX-2 inhibition. Plant polyphenol genistein (soy) by inhibition of NF- $\kappa$ B can increase the effectiveness of chemotherapy and radiation, effects proven in pancreatic cancer cells, lungs, prostate, melanoma, and leukemia. Resveratrol polyphenol from grapes has in more studies demonstrated the effect of suppressing proliferation of lymphoid and myeloid tumors, bowel cancer, breast cancer, prostate, pancreas, ovarian, cervix. Curcumin (Curcuma longa) expresses the expression of NF$\kappa B$ target genes (COX-2, iNOS, MMP-9, UPA, cyclin D1, EGFR) and suppresses the activation of NF- $\kappa B$. It potentiates cytotoxic effects of doxorubicin, 5-FU, and paclitaxel in prostate cancer cells. It modulates the MDR gene activity and thereby suppresses the drug efflux via P-gp, leading to chemosensitization. Green tea polyphenols (caffeine, EGCG, and flavonoids) inhibit the efflux of doxorubicin from Ehrlich ascites cancer cells. EGCG inhibits activation of the NF- $\kappa \mathrm{B}$ in the prostate, epidermoid, head and neck cancer cells and some breast cancer, and lung cancer. The amino acid teanine (glutamate-transporter inhibitor) has a synergistic effect with doxorubicin in the ovarian sarcoma and increases the activity of cisplatin, irinotecan, CP-11. The oral administration of teanine from green tea has the same effect. Flavo- 
piridol potentiates the effect of chemotherapy on breast and stomach cancer. It also increases the cytotoxic effect of paclitaxel, cytarabine, topotecan, doxorubicin, and etoposide, only when administered after treatment. The mechanism of action may include inhibition of NF- $\kappa \mathrm{B}$ and inhibition of NF- $\kappa B$ gene transcription. Silymarin on animal models protects against cardiotoxicity of an anthracycline, possibly by stabilizing the cell membrane or by capturing free radicals. In addition to synergistic effects with oncological therapy, polyphenols protect normal cells from chemotherapy / radiotherapy-induced toxicity. Curcumin has been shown to be protective in renal, cardiac and GI system damage caused by doxorubicin, by suppressing oxidative stress. Ginger reduces nausea caused by radiation and chemotherapy. (14)

\section{CONCLUSION}

Many cell mechanisms build resistance of tumor cell to antineoplastic treatment. That is probably the key to suboptimal results in the cytotoxic treatment of cancer. Thus, many natural products and parts of everyday nutrition, especially healthy nutritive regimens, are well known for their anticancer activity. This anticancer activity is in much no less than prevention or correction/disruption of cancer cell developed chemoresistance. All of the mentioned is to date recognized and described through the majority of the most frequent solid tumors and hemoblastoses, which gives an insight of how complex and dynamic the interaction of tumor cell and antitumor treatment, as well as any manipulation of it, can be. It also gives a hope that not everything depends on the nonselective, cytotoxic effect of chemo and radiotherapy used, but that there are ways of tricking cells mechanisms in developing their defense against treatment, and somewhat of it, we already witness, through development and usage of targeted therapies.

\section{REFERENCES}

1. Abdullah LN, Kai-Hua Chow E. 2013. Mechanisms of chemoresistance in cancer stem cells. Clin Transl Med. 2:3 doi: 10.1186/2001-1326-2-3

2. Liu S, Yi Z, Ling M, Shi J, Qiu Y, Yang S. 2014. Predictive potential of ABCB1, ABCC3, and GSTP1 gene polymorphisms on osteosarcoma survival after chemotherapy.Tumor Biol. 35:9897-9904. doi:10.1007/ s13277-014-1917-x
3. Sokke Umeshappa C, Zhu Y, Kalyanasundaram Bhanumathy K et al. 2015. Innate and Adoptive Immune Cells Contribute to Natural Resistance to Systemic Metastasis of B16 Melanoma. Cancer biotherapy and radiopharmaceuticals Vol.30;2 doi: 10.1089/cbr.2014.1736.

4. Itamochi H, Kigawa J, Terakawa N. 2008. Mechanisms of chemoresistance and poor prognosis in ovarian clear cell carcinoma. Japanese Cancer Association.doi: 10.1111/j.1349-7006.2008.00747. Japanese Cancer Association.

5. Traverso N, Ricciarelli R, Nitti et al. 2013. Role of Glutathione in Cancer Progression and Chemoresistance. Oxidative Medicine and Cellular Longevity, vol. 2013, Article ID 972913, 10 pages, 2013. doi: $10.1155 / 2013 / 972913$

6. Townsend DM, D Tew K. 2003. The role of glutathione-S-transferase in anti-cancer drug resistance. Oncogene. 22, 7369-7375

7. Brown K, Toker A. 2015. The phosphoinositide 3-kinase pathway and therapy resistance in cancer. https:// www.ncbi.nlm.nih.gov >... > PubMed Central

8. Sui X, Chen R, Wang Z, et al. 2013. Autophagy and chemotherapy resistance: a promising therapeutic target for cancer treatment. Cell Death Dis. 2013 Oct 10;4:e838. doi: 10.1038/cddis.2013.350.

9. Duru N, Candas D, Jiang G, Jian Li J. 2014. Breast cancer adaptive resistance: HER2 and cancer stem cell repopulation in a heterogeneous tumor society. J Cancer Res Clin Oncol.140:1-14.

10. Kapse-Mistry S, Govender T, Srivastava R, Wergeri M. 2014. Nanodrug delivery in reversing multidrug resistance in cancer cells.Frontiers in pharmacology.doi: 10.3389/fphar.2014.00159.

11. Eric W, Lam F, Gomes AR. 2014. Forkhead box transcription factors in cancer initiation, progression and chemotherapeutic drug response. Front. Oncol. https: //doi.org/10.3389/fonc.2014.00305

12. Eyre R, Harvey I, Stemke-Hale K, et al. 2014. Reversing paclitaxel resistance in ovarian cancer cells via inhibition of the ABCB1 expressing side population. Tumor Biol. 35:9879-9892.

13. Pisco AO, Jackson DA, Huang S. 2014. Reduced intracellular drug accumulation in drug-resistant leukemia cells is not only solely due to MDR-mediated efflux but also to decreased uptake. Front. Oncol. 31 https:// doi.org/10.3389/fonc.2014.00306.

14. Garg AK, Buchholz TA, Aggarwal B. 2005. Chemosensitization and Radiosensitization of Tumors by Plant Polyphenols. Antioxidants \& redox signaling, Vol.7;11,12.

Corresaponding author: Ljubica Vazdar, Department of Medical Oncology, Division of Radiotherapy and Medical Oncology, University Hospital for Tumors, Sestre milosrdnice University Hospital Center, Ilica 197, 10000 Zagreb,Croatia.e-mail: ljubica.vazdar@gmail.com 